
\title{
28 Research Square \\ Laterality of Blood Perfusion in the Lower Extremities after Drinking Saline at Different Temperatures
}

\section{Shuyong Jia}

Institute of Acupuncture and Moxibustion

\section{Qizhen Wang}

Institute of Basic Research in Clinical Medicine

Hongyan Li

Institute of Acupuncture and Moxibustion

\section{Xiaojing Song}

Institute of Acupuncture and Moxibustion, China Academy of Chinese Medical Sciences

\section{Shuyou Wang}

Institute of Acupuncture and Moxibustion, China Academy of Chinese Medical Sciences

\section{Weibo Zhang}

Institute of Acupuncture and Moxibustion

\section{Guangjun Wang ( $\nabla$ tjuwgj@gmail.com )}

Institute of Acupuncture and Moxibustion https://orcid.org/0000-0001-5344-4594

\section{Article}

Keywords: Laser Doppler blood perfusion, laterality, wavelet analysis, saline, EGG, ECG, dominant frequency, RMSSD

Posted Date: December 16th, 2020

DOI: https://doi.org/10.21203/rs.3.rs-112441/v3

License: (a) (i) This work is licensed under a Creative Commons Attribution 4.0 International License. Read Full License 


\section{Abstract}

Background: Skin blood flux (SkBF) changes caused by drinking cold water are generally associated with vagal tone and osmotic factors in the digestive system. However, the distribution and regulation of bilateral blood flow are not symmetrical but exhibit a certain laterality. The aim of this study was to analyze the laterality of SkBF after drinking saline (0.9\%) at different temperatures by monitoring blood flux in the bilateral lower extremities.

Methods: A total of 60 subjects were recruited for this study, and all subjects completed all measurements. Subjects were randomly divided into a $4{ }^{\circ} \mathrm{C}$ group, $10^{\circ} \mathrm{C}$ group and $30{ }^{\circ} \mathrm{C}$ group. For every subject, skin blood perfusion of bilateral Zusanli acupoints (ST 36) was recorded simultaneously before and after drinking $500 \mathrm{ml}$ of $0.9 \%$ saline using a PeriFlux System 5000. The electrogastrogram (EGG) was also monitored, and the dominant frequency of the EGG and heart rate variability were analyzed.

Results: The results indicated that after drinking saline at different temperatures, the laterality index of SkBF at the lower extremities was different. Drinking $30^{\circ} \mathrm{C}$ saline can increase the laterality index of the lower extremities. Stimulation at $4{ }^{\circ} \mathrm{C}$ and $10{ }^{\circ} \mathrm{C}$ resulted in a decrease in the DF of the EGG and an increased RMSSD of the RR interval. Although this laterality is mainly contributed to by frequency interval $V$, there was a weak negative correlation between the laterality index of frequency interval I or II and RMSSD.

Conclusion: There was laterality of blood perfusion in the lower extremities after drinking saline at different temperatures.

\section{Background}

Although humans prefer to drink water at a temperature below standard room temperature ${ }^{1}$, studies about the effect of water temperature on blood flux are scarce. Only a few reports have studied the effects of water temperature on healthy humans ${ }^{2-4}$. Scientists have suggested that the water effect does not depend on gastric distension, but on the water osmolality, which could cause an autonomic cardiovascular response in humans through osmotic sensing nerve fibers in the intestinal or portal circulation $^{5,6}$. On the other hand, the results shown that water intake activates distinct gastrointestinal vagal afferent in a temperature-dependent pattern and might affect cardiac vagal tone ${ }^{7}$.

A previous work suggested that oral glucose intake inhibits hypothalamic neuronal activity than intravenous (IV) glucose administration more effectively ${ }^{8}$, but oral intake saline results in minimal variations in serum albumin, hematocrit, and hemoglobin compared to IV infusion ${ }^{9}$. These studies indicated that, in addition to osmotic pressure and temperature mechanisms, the different autonomic responses of digestive tract might result in systemic regulation of peripheral blood perfusion. Furthermore, some works have indicated that the cutaneous microvasculature mirrors the vascular function of other parts of the body ${ }^{10-12}$. Therefore, skin blood flow can be used to explore the regulation 
of gastrointestinal autonomic function after stimulation. According to previous studies ${ }^{13,14}$, the cutaneous blood perfusion of both sides is different.

Therefore, we hypothesized that ingestion of saline at different temperatures influences human cutaneous blood perfusion, which will lead to lateralization of the regulation of blood perfusion. To test these hypotheses, we compared, with a randomized control design, the cutaneous blood perfusion changes in response to different temperatures of saline and additionally evaluated their potentially differential impacts on EGG DF and cardiovascular variables.

\section{Results}

In this study, a total of 60 subjects were recruited, and all subjects were included in the final statistical analysis. The order of stimulations was randomly generated for each subject. Detailed information on the subjects is summarized in Table $1\left(4^{\circ} \mathrm{C}, \mathrm{N}=20 ; 10^{\circ} \mathrm{C}, \mathrm{N}=20\right.$ and $\left.30^{\circ} \mathrm{C}, \mathrm{N}=20\right)$.

Table 1. Subject's sex composition and average age, height and weight

\begin{tabular}{|c|c|c|c|c|c|}
\hline Group & $\mathrm{n}$ & $\begin{array}{l}\text { Sex } \\
\text { (female/male) }\end{array}$ & $\begin{array}{l}\text { Age } \\
\text { (years, mean } \pm \text { SD) }\end{array}$ & $\begin{array}{l}\text { Height } \\
(\mathrm{cm}, \text { mean } \pm \mathrm{SD})\end{array}$ & $\begin{array}{l}\text { Weight } \\
(\mathrm{kg}, \text { mean } \pm \mathrm{SD})\end{array}$ \\
\hline $4^{\circ} \mathrm{C}$ & 20 & $17 / 3$ & $26.90 \pm 2.72$ & $164.95 \pm 7.19$ & $59.55 \pm 9.29$ \\
\hline $10^{\circ} \mathrm{C}$ & 20 & $18 / 2$ & $24.90 \pm 2.54$ & $163.60 \pm 5.58$ & $56.20 \pm 10.73$ \\
\hline $30^{\circ} \mathrm{C}$ & 20 & $17 / 3$ & $25.95 \pm 1.24$ & $161.85 \pm 6.11$ & $54.60 \pm 13.57$ \\
\hline
\end{tabular}

\section{EGG and ECG results}

The results of EGG analysis are shown in Fig 1, the recording electrode position is shown in Fig $1 \mathrm{~A}$, and the raw data of 8-channel gastrointestinal electrical signals recorded are shown in Fig 1B. The spectral analysis of each signal is shown in Fig $1 \mathrm{C}$. The statistical results of the main frequency corresponding to the maximum power in each subject's 8-channel gastrointestinal electrical signals are shown in Fig 1D. In the resting state, there was no significant difference in the dominant frequency of the subjects.

Cold stimulation of the digestive tract will not only cause a change in the electrogastrogram but also be accompanied by systemic reactions. The raw data of ECG and RR interval signal are shown in Fig $2 \mathrm{~A}$ and Fig 2B, respectively. The changes in the RR interval and RMSSD were also analyzed. The results showed that the RR interval (Fig 2C) and RMSSD (Fig 2D) were increased with both $4{ }^{\circ} \mathrm{C}$ and $10{ }^{\circ} \mathrm{C}$ stimulation compared with $30^{\circ} \mathrm{C}$ stimulation.

\section{Skin blood flux}

The average responses of blood perfusion to stimulation at different temperatures over time are shown in Fig 3. The recording position of both sides for blood perfusion is shown in Fig 3A, the raw data of bilateral blood perfusion are shown in Fig $3 \mathrm{~B}$, the absolute value of bilateral blood flow difference is 
shown in Fig 3C, and the laterality change in bilateral blood perfusion under different temperature stimulation conditions is shown in Fig 3D. In the first 10 min after stimulation, there was a significant difference between the changes induced by $30^{\circ} \mathrm{C}$ stimulation and $4{ }^{\circ} \mathrm{C}$ stimulation. At the second and third 10 min after stimulation, there were significant differences between the changes induced by $30^{\circ} \mathrm{C}$ stimulation and those caused by $4{ }^{\circ} \mathrm{C}$ and $10{ }^{\circ} \mathrm{C}$. However, there were no significant changes in the changes induced by $4{ }^{\circ} \mathrm{C}$ and $10^{\circ} \mathrm{C}$.

Because the blood flow signal is composed of many components, bilateral blood flow was transformed by wavelet (Fig $4 \mathrm{~A}$ ), and the laterality index in different frequency intervals was calculated. The results showed that the difference was mainly reflected in frequency $V(0.4-1.6 \mathrm{~Hz})$ (Fig $4 \mathrm{~F})$. There was no significant difference between other frequency intervals (Fig 4 B-E).

To further analyze the possibility of blood flow laterality, we analyzed the correlation between these parameters. First, we confirmed that there was an apparent correlation between the DF and RMSSD (S Fig $1 \mathrm{~A})$ at $4{ }^{\circ} \mathrm{C}$ stimulation. However, there was no apparent correlation between the laterality index and the DF (S Fig 2A-C) or RMSSD (S Fig 2D-F). After wavelet transformation, we found that there was a negative correlation between RMSSD and the laterality index of frequencies I and II at $4{ }^{\circ} \mathrm{C}$ stimulation (Fig $5 \mathrm{~A}$ and D), which was independent of other frequency intervals (Fig 5G, $J$ and M). There was a positive correlation between RMSSD and the laterality index of frequency II (Fig 5F), rather than other frequencies (Fig $5 \mathrm{C}, \mathrm{I}, \mathrm{L}$ and $\mathrm{O}$ ) at $30^{\circ} \mathrm{C}$ stimulation. There was no correlation between the laterality index of each frequency and RMSSD at $10^{\circ} \mathrm{C}$ (Fig. 5B, E, H, K and N). However, there is no correlation between the laterality index and DF in any frequency interval (S Fig 3 ).

\section{Discussion}

As Fig 6 shows, the main significance of current work is that there was response laterality of blood perfusion in the lower extremities after drinking saline at different temperatures, which means that autonomic nerve function is different between left and right in the process of blood flow regulation. The present study demonstrated that drinking saline at different temperatures produced the changes of cutaneous vascular movement, which means that regulation of cutaneous vascular might play an important role in water temperature digestion. A previous study ${ }^{5}$ indicated that the water effect does not depend on gastric distension, but on the water osmolality, which could cause an autonomic cardiovascular response in humans through osmotic sensing nerve fibers in the intestinal or portal circulation $^{5,6}$. However, in the current study, osmotic pressure of saline at different temperatures is same, it is difficult to conclude that the change in sympathetic tone is caused by osmolality.

In peripheral, small changes in cutaneous vascular blood perfusion can shift cardiovascular control. A decrease in the skin blood perfusion can lead to relative changes of sympathetic activation in peripheral ${ }^{15}$. Which can be explained by the activation of temperature sensitive vagal afferent fibers found in the digestive tract ${ }^{16}$. Water intake seems to activate different gastrointestinal vagal afferent fibers in a temperature dependent manner and may affect subsequent cardiac vagal tone ${ }^{7}$. Our results 
demonstrated that different water temperatures not only decreased the DF of EGG but also were associated with a change in the mean RR interval and RMSSD. However, as shown in Fig 6, there is no direct linear relationship between bilateral blood flow laterality and RMSSD, but after decomposing the blood flow components, it is found that there is a linear relationship between specific components and RMSSD. It is suggested that the regulation of peripheral blood flow induced by stimulation at different temperatures is selective. In the present study, the change trend of SkBF at bilateral ST 36 was different after drinking saline at different temperatures. As in previous findings ${ }^{13,17}$, this phenomenon is defined as laterality and can be described quantitatively by the laterality index.

Laterality tends to focus on the differentiation of left and right handedness and cerebral hemisphere function. However, little attention has been given to the lateralization of blood flow distribution. Our previous studies have found that there are significant differences in the distribution and regulation of blood flow in the same parts of both sides of the body ${ }^{13,14}$, and such results have been confirmed by other research groups ${ }^{18}$. A previous study indicated that in young subjects, sympathetic vasoconstrictor activation after drinking water was not accompanied by an increase in arterial blood pressure ${ }^{19}$, which suggested that the change in vascular tone in the limbs may be partially compensated by opposing changes in other vascular beds ${ }^{19}$. Therefore, it is acceptable that the distribution of bilateral blood flow and its variation are asymmetric.

\section{Methods}

\section{Inclusion and exclusion criteria}

Eligible subjects had to be heathy and between the ages of 18 and 60 years. All participants were requested to avoid alcohol, tea and coffee for at least 24 hours prior to the test. None of the subjects had any diseases or were taking any medication affecting cardiovascular or autonomic regulation.

\section{Participants and groups}

A total of 60 healthy subjects were enrolled in the study, and all subjects completed measurements and were included in the statistical analysis. The general characters are presented in Table 1. All experiments took place in a quiet, temperature-controlled $\left(24-26^{\circ} \mathrm{C}\right)$ laboratory. On arrival at the laboratory, subjects were asked to empty their bladders. Following a period of cardiovascular stability (40 min), a baseline recording was then made for at least $15 \mathrm{~min}$. Then, over a 5 min period, the test subjects ingested $500 \mathrm{~mL}$ of $0.9 \%$ saline at different temperatures, and EGG and skin blood flux were monitored.

\section{Electrogastrogram measurement protocol and analysis}

The subjects maintained a supine position. Eight cutaneous electrodes were placed on the abdomen of the participant and connected to DC amplifiers. The EGG recordings were processed with a NeurOne system (NeurOne, MEGA electronics Ltd, Finland). The data were digitized with a sampling rate of 10000 
$\mathrm{Hz}$ and then downsampled at $1000 \mathrm{~Hz}$. EGG data were analyzed with the FieldTrip toolbox ${ }^{20}$, and the analysis code for EGG analysis was provided by Rebollo, $\mathrm{I}^{21}$.

\section{RMSSD and mean RR interval analysis}

The analysis method can be referenced in our previous study ${ }^{22-24}$. The raw data of channel one were exported in EDF format, imported into Kubio HRV software and analyzed ${ }^{25}$. The analysis parameter was default. The root mean square of successive differences (RMSSD) was given by (1).

$$
R M S S D=\sqrt{\frac{1}{N-1} \sum_{n=1}^{N-1}\left(R R_{n+1}-R R_{n}\right)^{2}}
$$

\section{Protocol for measurement of blood perfusion}

Both legs were exposed, and bilateral Zusanli acupoints (ST 36) were marked by senior acupuncture doctors. Blood perfusion signals were recorded using a PeriFlux System 5000 (Perimed AB, Stockholm, Sweden) with a $64 \mathrm{~Hz}$ sample rate and $0.2 \mathrm{~s}$ time constant. An optical fiber probe connected with a Periflux 5000 was used to illuminate and collect the scattered light from the skin tissue. The probe was attached to the surface of interest with two-sided adhesive tape.

\section{Mean blood perfusion analysis and wavelet analysis}

The recorded file of each subject was opened in PeriSoft software for Windows (version 2.5.5, Perimed, Sweden). The detailed data were exported in txt format and then imported into MATLAB software and analyzed. The laterality index of blood flux every $10 \mathrm{~min}$ on both sides of ST36 was calculated as (1).

$$
\text { Laterality Index }=\frac{\text { mean }\left(\mid \operatorname{Post}_{L}-\text { Post }_{R} \mid\right)}{\operatorname{mean}\left(\left|\operatorname{Pre}_{L}-\operatorname{Pre}_{R}\right|\right)} \times 100
$$

Previous studies indicated that blood flux oscillations at frequencies from 0.0095 to $1.6 \mathrm{~Hz}$ might reflect different physiological rhythms ${ }^{26}$, which can be separated into five frequency bands in the frequency domain ${ }^{27-30}$. In the present study, wavelet analysis was performed on the blood flux signal (10 min) using a Morlet wavelet (The Mathworks Inc., Natick, MA, USA). For every frequency interval, the laterality index was also calculated as (2).

\section{Statistical analysis}

Data are presented as the mean $\pm S E$. Mixed repeated-measures ANOVA was used to analyze betweensubject factors with R software. All correlation analyses were conducted using MATLAB software (MathWorks, Natick, Massachusetts, USA). All reported $P$ values were two-sided, and the level of significance was defined as $P<0.05$. 


\section{Conclusion}

There were different responses of blood perfusion in the lower extremities after ingestion of saline at different temperatures.

\section{List Of Abbreviations}

SkBF: skin blood flux;

DF: dominant frequency;

RMSSD: root mean square of successive differences;

ST 36: Zusanli acupoint;

ECG: electrocardiogram;

EGG: electrogastrogram

HRV: heart rate variability;

TCM: Traditional Chinese Medicine;

Fig: figure;

SD: standard deviation;

SE: standard error;

ANOVA: analysis of variance

\section{Declarations}

\section{Data availability}

The majority of supporting data are presented within this article and its Supplement. Raw data are available from the corresponding author upon reasonable request.

\section{Ethics approval and consent to participate}

This study was approved by the Institutional Research Ethics Boards of Acupuncture \& Moxibustion, China Academy of Chinese Medical Sciences. In accordance with the Declaration of Helsinki囚each subject provided informed consent and had an adequate understanding of the procedure and purpose of this study. 


\section{Authors' contributions}

GJ Wang carried out the design and participated in data collection and analysis. SY Jia, HY Li, XJ Song, SY Wang and WB Zhang participated in data collection. QZ Wang analyzed part of data. All authors contributed to the final manuscript and approved the final version.

\section{Competing interests}

The authors declare that they have no competing interests.

\section{References}

1 Burdon, C. A., Johnson, N. A., Chapman, P. G. \& O'Connor, H. T. Influence of beverage temperature on palatability and fluid ingestion during endurance exercise: a systematic review. Int J Sport Nutr Exerc Metab 22, 199-211 (2012).

2 Boschmann, M. et al. Water-induced thermogenesis. J Clin Endocrinol Metab 88, 6015-6019, doi:10.1210/jc.2003-030780 (2003).

3 Brown, C. M., Dulloo, A. G. \& Montani, J. P. Water-induced thermogenesis reconsidered: the effects of osmolality and water temperature on energy expenditure after drinking. J Clin Endocrinol Metab 91, 3598-3602, doi:10.1210/jc.2006-0407 (2006).

4 Wang, G. et al. Response of Blood Perfusion at ST 36 Acupoint after Drinking Cold Glucose or Saline Injection. Evidence-based complementary and alternative medicine : eCAM 2017, 4212534, doi:10.1155/2017/4212534 (2017).

5 May, M. \& Jordan, J. The osmopressor response to water drinking. Am J Physiol Regul Integr Comp Physio/300, R40-46, doi:10.1152/ajpregu.00544.2010 (2011).

6 Brown, C. M., Barberini, L., Dulloo, A. G. \& Montani, J. P. Cardiovascular responses to water drinking: does osmolality play a role? Am J Physiol Regul Integr Comp Physiol 289, R1687-1692, doi:10.1152/ajpregu.00205.2005 (2005).

7 Girona, M., Grasser, E. K., Dulloo, A. G. \& Montani, J. P. Cardiovascular and metabolic responses to tap water ingestion in young humans: does the water temperature matter? Acta physiologica 211, 358370, doi:10.1111/apha.12290 (2014).

8 Smeets, P. A. et al. Oral glucose intake inhibits hypothalamic neuronal activity more effectively than glucose infusion. Am J Physiol Endocrinol Metab 293, E754-758, doi:10.1152/ajpendo.00231.2007 (2007). 
de Aguilar-Nascimento, J. E., Valente, A. C., Oliveira, S. S., Hartmann, A. \& Slhessarenko, N. Changes in body composition, hematologic parameters, and serum biochemistry after rapid intravenous infusion or oral intake of 2 liters of $0.9 \%$ saline solution in young healthy volunteers: randomized crossover study. World J Surg 36, 2776-2781, doi:10.1007/s00268-012-1756-0 (2012).

10 Holowatz, L. A., Thompson-Torgerson, C. S. \& Kenney, W. L. The human cutaneous circulation as a model of generalized microvascular function. J. Appl. Physiol. 105, 370-372, doi:10.1152/japplphysiol.00858.2007 (2008).

11 Stewart, J. et al. Noninvasive interrogation of microvasculature for signs of endothelial dysfunction in patients with chronic renal failure. Am. J. Physiol.-Heart Circul. Physiol. 287, H2687-H2696, doi:10.1152/ajpheart.00287.2004 (2004).

12 Rossi, M. et al. Investigation of skin vasoreactivity and blood flow oscillations in hypertensive patients: effect of short-term antihypertensive treatment. J. Hypertens. 29, 1569-1576, doi:10.1097/HJH.0b013e328348b653 (2011).

13 Wang, G., Han, J., Litscher, G. \& Zhang, W. System identification algorithm analysis of acupuncture effect on mean blood flux of contralateral hegu acupoint. Evidence-based complementary and alternative medicine : eCAM 2012, 951928, doi:10.1155/2012/951928 (2012).

14 Wang, G., Tian, Y., Jia, S., Wang, Z. \& Zhang, W. Laterality and coherence analysis of Laser Doppler Flowmetry signals in bilateral Nèi guān(PC6 $\mathrm{PC})$ : a potential non-invasive method to assess microcirculatory changes in different ages. World Journal of Acupuncture-Moxibustion 27, 47-52 (2017).

15 Eicke, B. M., Milke, K., Schlereth, T. \& Birklein, F. Comparison of continuous wave Doppler ultrasound of the radial artery and laser Doppler flowmetry of the fingertips with sympathetic stimulation. J Neurol 251, 958-962, doi:10.1007/s00415-004-0471-7 (2004).

16 Gupta, B. N., Nier, K. \& Hensel, H. Cold-sensitive afferents from the abdomen. Pflugers Arch 380, 203-204 (1979).

17 Wang, G. et al. Acupuncture Point Laterality: Evidence and Perspective. Integrative Medicine International 1, 102-107 (2014).

18 Mezentseva, L. V. \& Pertsov, S. S. Correlation-and-Spectral Analysis of Time Series for Microcirculatory Parameters in Vessels of Symmetrical Organs. Bull Exp Biol Med 166, 301-305, doi:10.1007/s10517-019-04337-y (2019).

19 Scott, E. M., Greenwood, J. P., Stoker, J. B., Gilbey, S. G. \& Mary, D. A. Water drinking and sympathetic activation. Lancet 356, 2013, doi:10.1016/S0140-6736(05)72987-1 (2000).

20 Oostenveld, R., Fries, P., Maris, E. \& Schoffelen, J. M. FieldTrip: Open Source Software for Advanced Analysis of MEG, EEG, and Invasive Electrophysiological Data. Comput Intel Neurosc, doi:Artn 
21 Wolpert, N., Rebollo, I. \& Tallon-Baudry, C. Electrogastrography for psychophysiological research: Practical considerations, analysis pipeline, and normative data in a large sample. Psychophysiology 57, e13599, doi:10.1111/psyp.13599 (2020).

22 Wang, G., Tian, Y., Jia, S., Zhou, W. \& Zhang, W. Acupuncture regulates the heart rate variability. J Acupunct Meridian Stud 8, 94-98, doi:10.1016/j.jams.2014.10.009 (2015).

23 Guangjun, W., Yuying, T., Shuyong, J., Wenting, Z. \& Weibo, Z. Bilateral hegu acupoints have the same effect on the heart rate variability of the healthy subjects. Evidence-based complementary and alternative medicine : eCAM 2014, 106940, doi:10.1155/2014/106940 (2014).

24 Wang, G., Tian, Y., Jia, S., Zhou, W. \& Zhang, W. Pilot study of acupuncture point laterality: evidence from heart rate variability. Evidence-based complementary and alternative medicine : eCAM 2013, 476064, doi:10.1155/2013/476064 (2013).

25 Niskanen, J. P., Tarvainen, M. P., Ranta-Aho, P. O. \& Karjalainen, P. A. Software for advanced HRV analysis. Comput Methods Programs Biomed 76, 73-81, doi:10.1016/j.cmpb.2004.03.004 (2004).

26 Bernardi, L. et al. Relationship between phasic changes in human skin blood flow and autonomic tone. Microvasc Res 37, 16-27 (1989).

27 Hsiu, H., Hsu, W. C., Hsu, C. L. \& Huang, S. M. Assessing the effects of acupuncture by comparing needling the hegu acupoint and needling nearby nonacupoints by spectral analysis of microcirculatory laser Doppler signals. Evid-Based Compl Alt 2011, 435928, doi:10.1093/ecam/neq073 (2011).

28 Thorn, C. E., Matcher, S. J., Meglinski, I. V. \& Shore, A. C. Is mean blood saturation a useful marker of tissue oxygenation? Am. J. Physiol.-Heart Circul. Physiol. 296, H1289-H1295, doi:10.1152/ajpheart.01192.2008 (2009).

29 Bernjak, A., Clarkson, P. B., McClintock, P. V. \& Stefanovska, A. Low-frequency blood flow oscillations in congestive heart failure and after beta1-blockade treatment. Microvasc Res 76, 224-232, doi:10.1016/j.mvr.2008.07.006 (2008).

30 Kvandal, P. et al. Low-frequency oscillations of the laser Doppler perfusion signal in human skin. Microvasc Res 72, 120-127, doi:10.1016/j.mvr.2006.05.006 (2006).

\section{Figures}



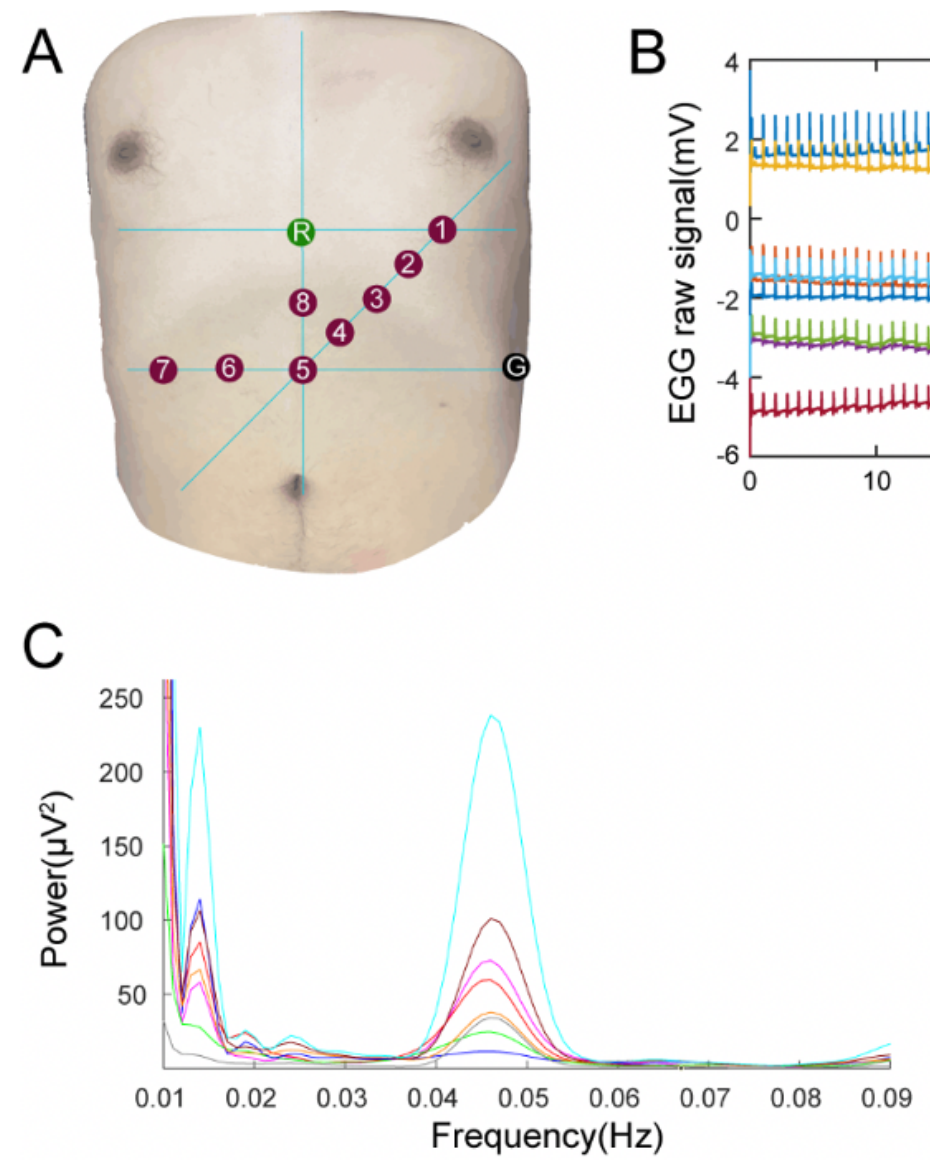
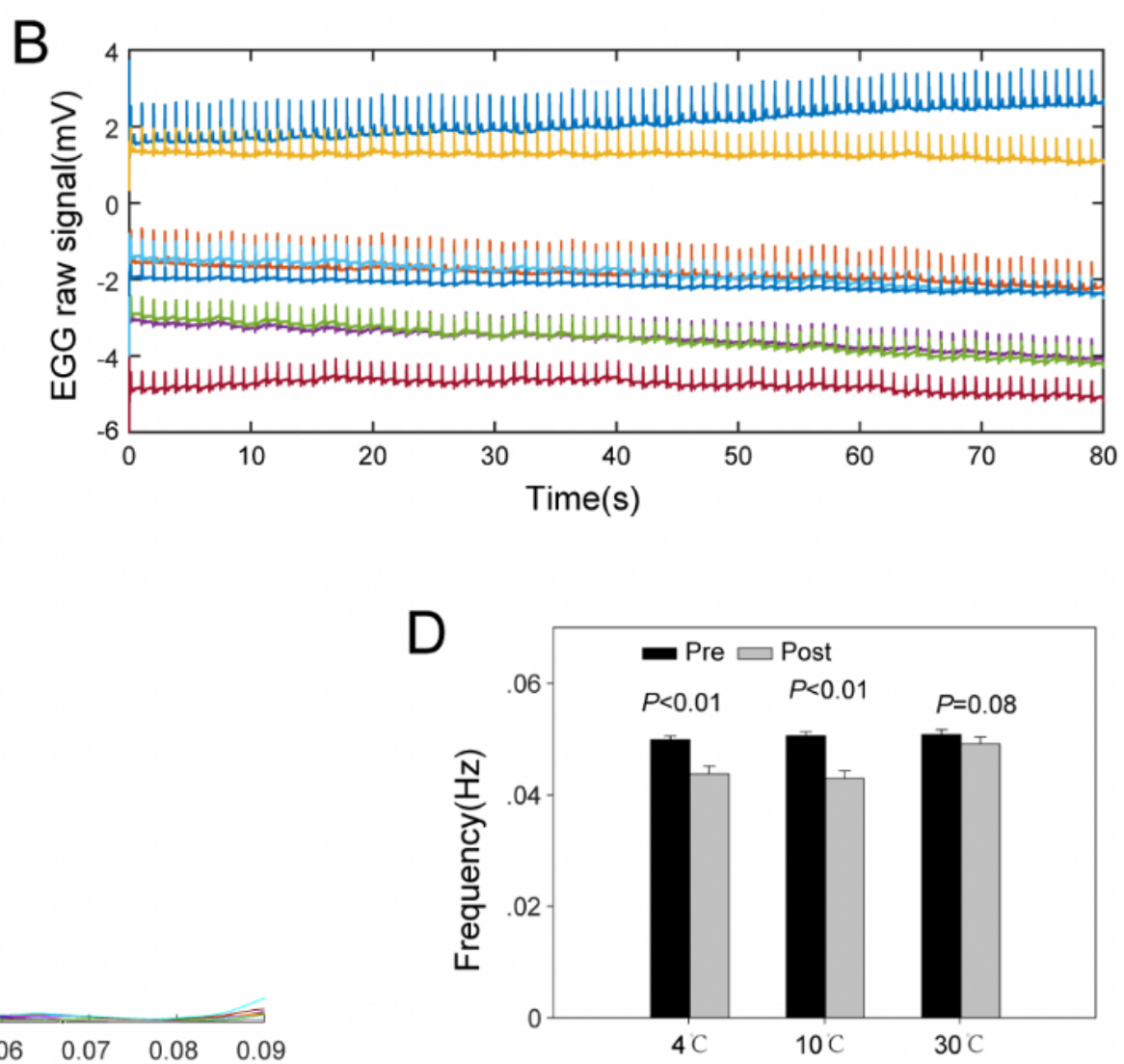

\section{Figure 1}

EGG power spectra changes. (A) Cutaneous electrode position, red indicates recording electrodes, green indicates reference electrode; black indicates ground electrode; (B) raw data of EGG; (C) power spectra of EGG; (D) EGG peak frequency before and after stimulation. Before stimulation, $F(2,57)=0.38, P=0.6884$; after stimulation, $\mathrm{F}(2,57)=6.45, \mathrm{P}=0.003$; for $4{ }^{\circ} \mathrm{C}$ stimulation, $\mathrm{t}=3.9819 \otimes \mathrm{P}<0.001$ (Pre VS Post, paired $\mathrm{t}$ test); for $10{ }^{\circ} \mathrm{C}$ stimulation, $\mathrm{t}=4.9807 \otimes \mathrm{P}<0.001$ (Pre VS Post, paired $\mathrm{t}$ test); for $30^{\circ} \mathrm{C}$ stimulation, $\mathrm{t}=1.8492 \rrbracket$ $\mathrm{P}=0.08$ (Pre VS Post, paired $\mathrm{t}$ test). 

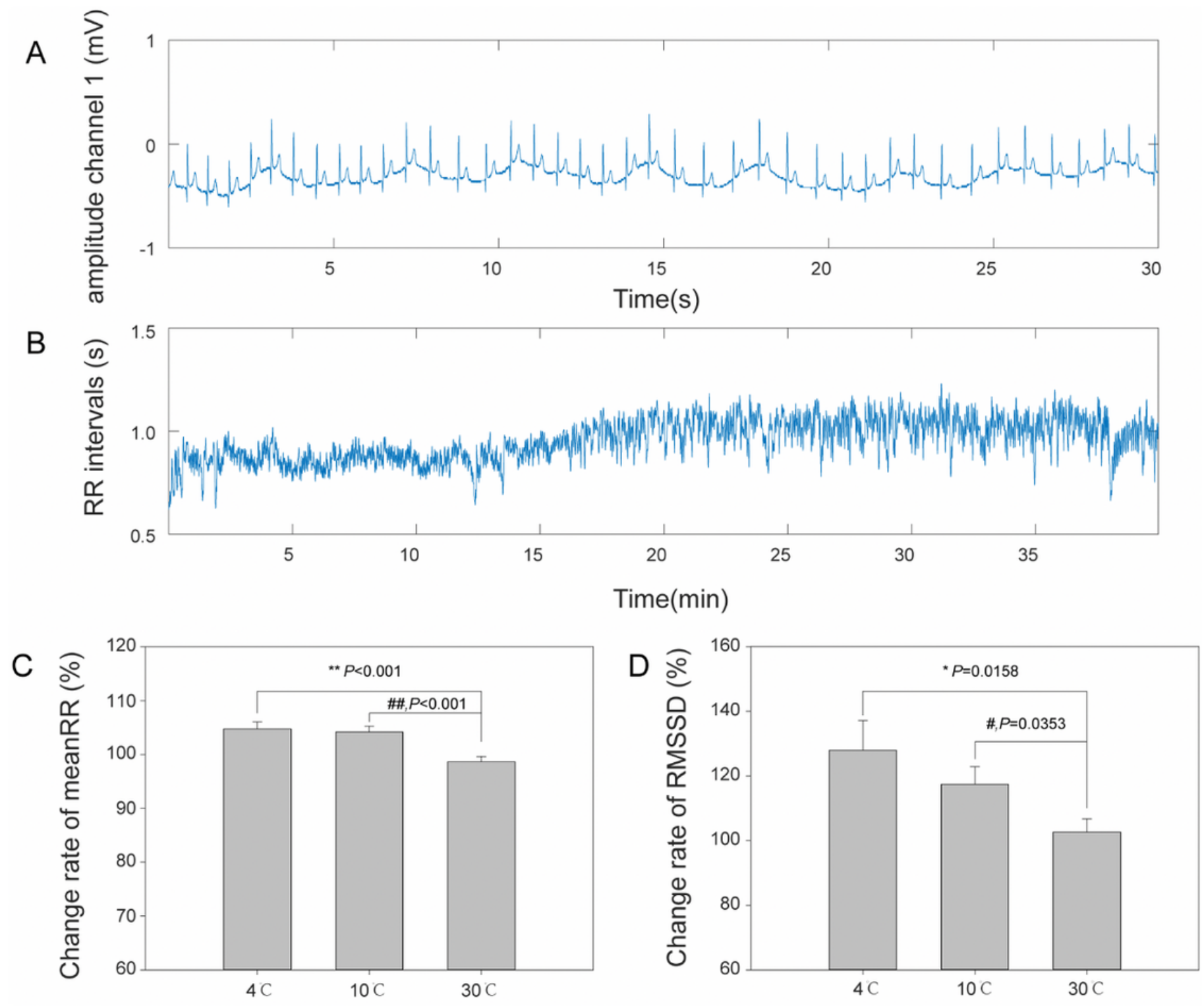

Figure 2

Change in HRV. (A) ECG signal from channel 1. (B) RR intervals of ECG. (C) Change rate of mean RR, $F(2,57)=8.73, P=0.0005, * \star, P<0.01\left(4{ }^{\circ} \mathrm{C}\right.$ VS $\left.30{ }^{\circ} \mathrm{C}\right)$; \#\#, $\mathrm{P}<0.01\left(10^{\circ} \mathrm{C}\right.$ VS $\left.30^{\circ} \mathrm{C}\right)$. (D) Change rate of RMSSD, $F(2,57)=3.75, \mathrm{P}=0.029 . *, \mathrm{P}<0.05,\left(4{ }^{\circ} \mathrm{C}\right.$ VS $\left.30{ }^{\circ} \mathrm{C}\right)$; $\#, \mathrm{P}<0.05,\left(10^{\circ} \mathrm{C}\right.$ VS $\left.30{ }^{\circ} \mathrm{C}\right)$. All values are reported as the mean $\pm \mathrm{SE}$.
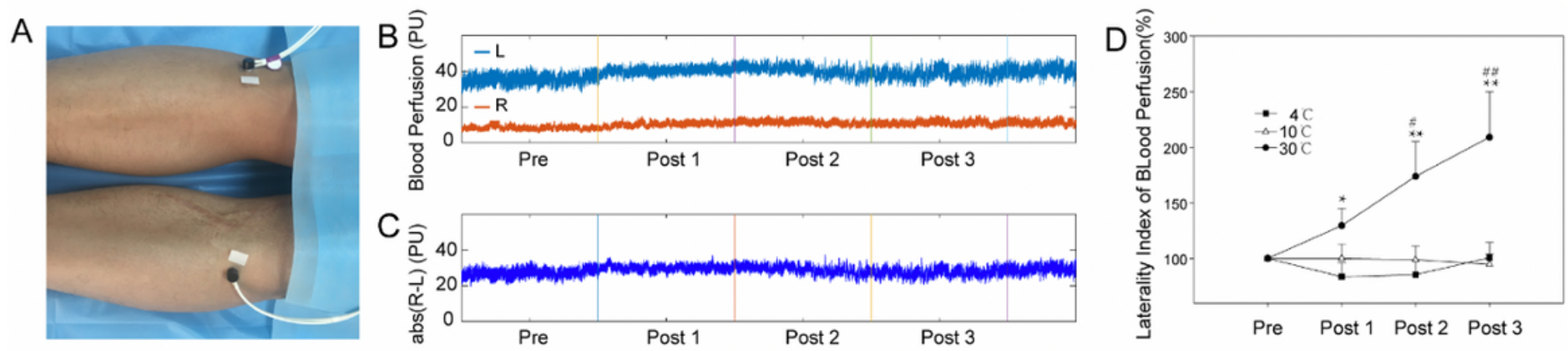


\section{Figure 3}

Blood perfusion in both sides. (A) Recording position at ST 36. (B) Raw data of blood flux in both sides. (C) The absolute value of the difference between two sides. (D) Laterality index of blood perfusion. $F(2,57)=5.749, \mathrm{P}<0.001 ; *, \mathrm{P}<0.05,{ }^{*}, \mathrm{P}<0.01\left(4{ }^{\circ} \mathrm{C}\right.$ VS $\left.30^{\circ} \mathrm{C}\right)$; \#, $\mathrm{P}<0.05, \# \#, \mathrm{P}<0.01\left(10^{\circ} \mathrm{C}\right.$ VS $\left.30{ }^{\circ} \mathrm{C}\right)$. All values are reported as the mean \pm SE.

A

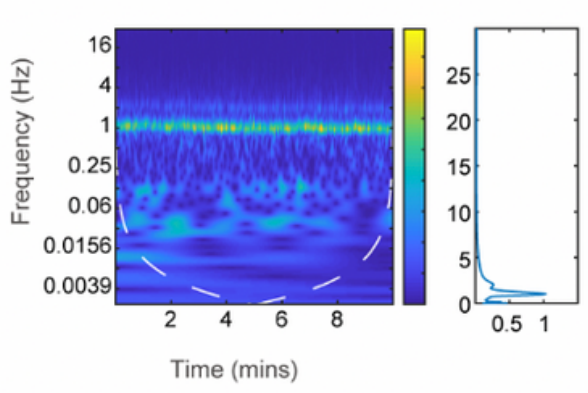

D

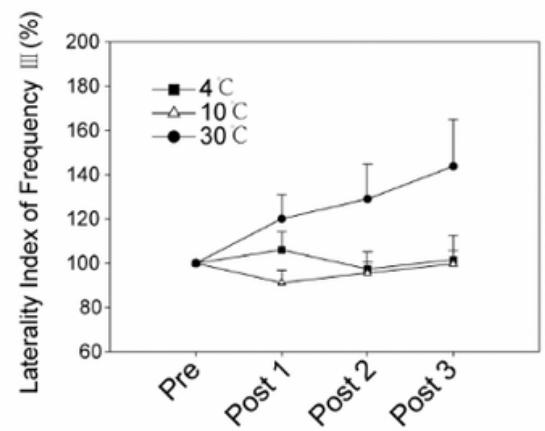

B

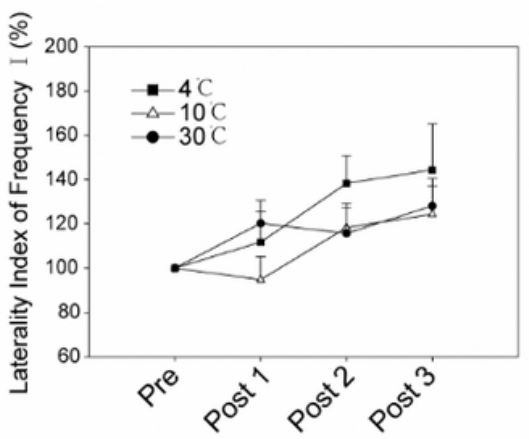

E

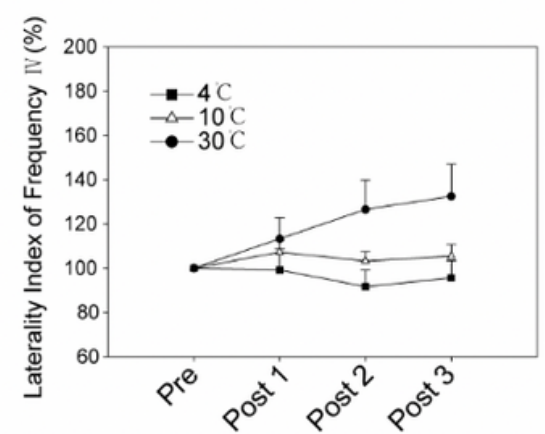

C

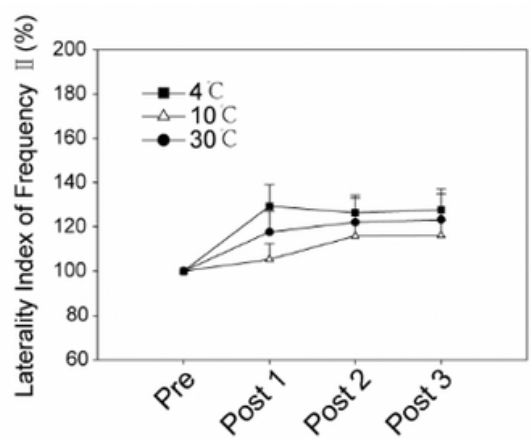

$\mathrm{F}$

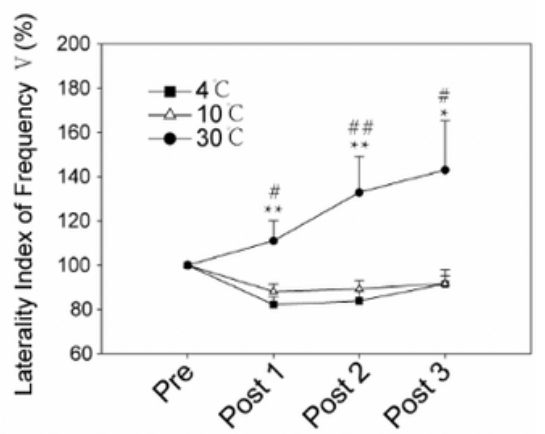

\section{Figure 4}

Change rate of different frequency intervals transformed by wavelet. (A) Wavelet analysis of blood flux.

(B) Frequency interval I $(0.0095-0.02 \mathrm{~Hz}), F(2,57)=0.723, P=0.49$. (C) Frequency interval II $(0.02-0.06 \mathrm{~Hz})$, $F(2,57)=0.952, P=0.392$. (D) Frequency interval III $(0.06-0.15 \mathrm{~Hz}), F(2,57)=3.288, P=0.0445$. (E) Frequency interval IV $(0.15-0.4 \mathrm{~Hz}), F(2,57)=2.746, P=0.0727$. (F) Frequency interval $V(0.4-1.6 \mathrm{~Hz}), F(2,57)=6.085, P$ $=0.00403 . *, P<0.05, * *, P<0.01\left(4{ }^{\circ} \mathrm{C}\right.$ VS $\left.30{ }^{\circ} \mathrm{C}\right) ; \#, \mathrm{P}<0.05, \# \#, \mathrm{P}<0.01\left(10^{\circ} \mathrm{C}\right.$ VS $\left.30{ }^{\circ} \mathrm{C}\right)$. All values are reported as the mean \pm SE. 


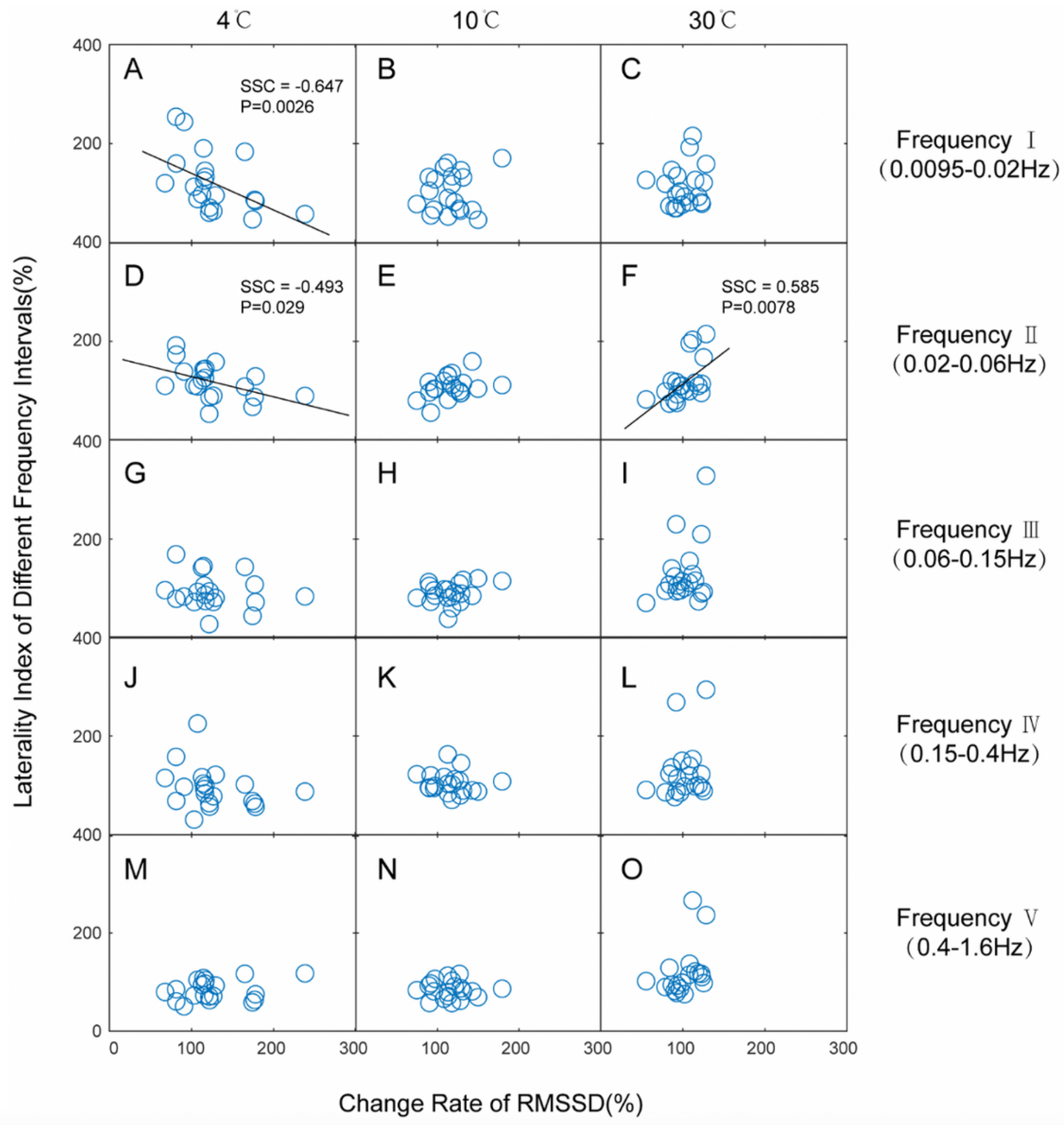

Figure 5

Relationship between laterality index of different frequency intervals and change rate of RMSSD. (A). Frequency I at $4{ }^{\circ} \mathrm{C}$. SCC $=-0.647, P=0.0026$. (B). Frequency I at $10^{\circ} \mathrm{C}$. (C). Frequency I at $30^{\circ} \mathrm{C}$. (D) Frequency II at $4{ }^{\circ} \mathrm{C}$. SCC $=-0.493, \mathrm{P}=0.029$. (E) Frequency II at $10^{\circ} \mathrm{C}$. (F) Frequency II at $30^{\circ} \mathrm{C}$. SCC $=0.585$, $\mathrm{P}=0.0078$. (G) Frequency III at $4{ }^{\circ} \mathrm{C}$. (H) Frequency III at $10^{\circ} \mathrm{C}$. (I) Frequency III at $30^{\circ} \mathrm{C}$. (J) Frequency IV at 
$4{ }^{\circ} \mathrm{C}$. (K) Frequency IV at $10^{\circ} \mathrm{C}$. (L) Frequency IV at $30^{\circ} \mathrm{C}$. (M) Frequency $\mathrm{V}$ at $4{ }^{\circ} \mathrm{C}$. (N) Frequency $\mathrm{V}$ at 10 ${ }^{\circ} \mathrm{C}$. (O) Frequency $\mathrm{V}$ at $30^{\circ} \mathrm{C}$. SCC, Spearman's correlation coefficient.

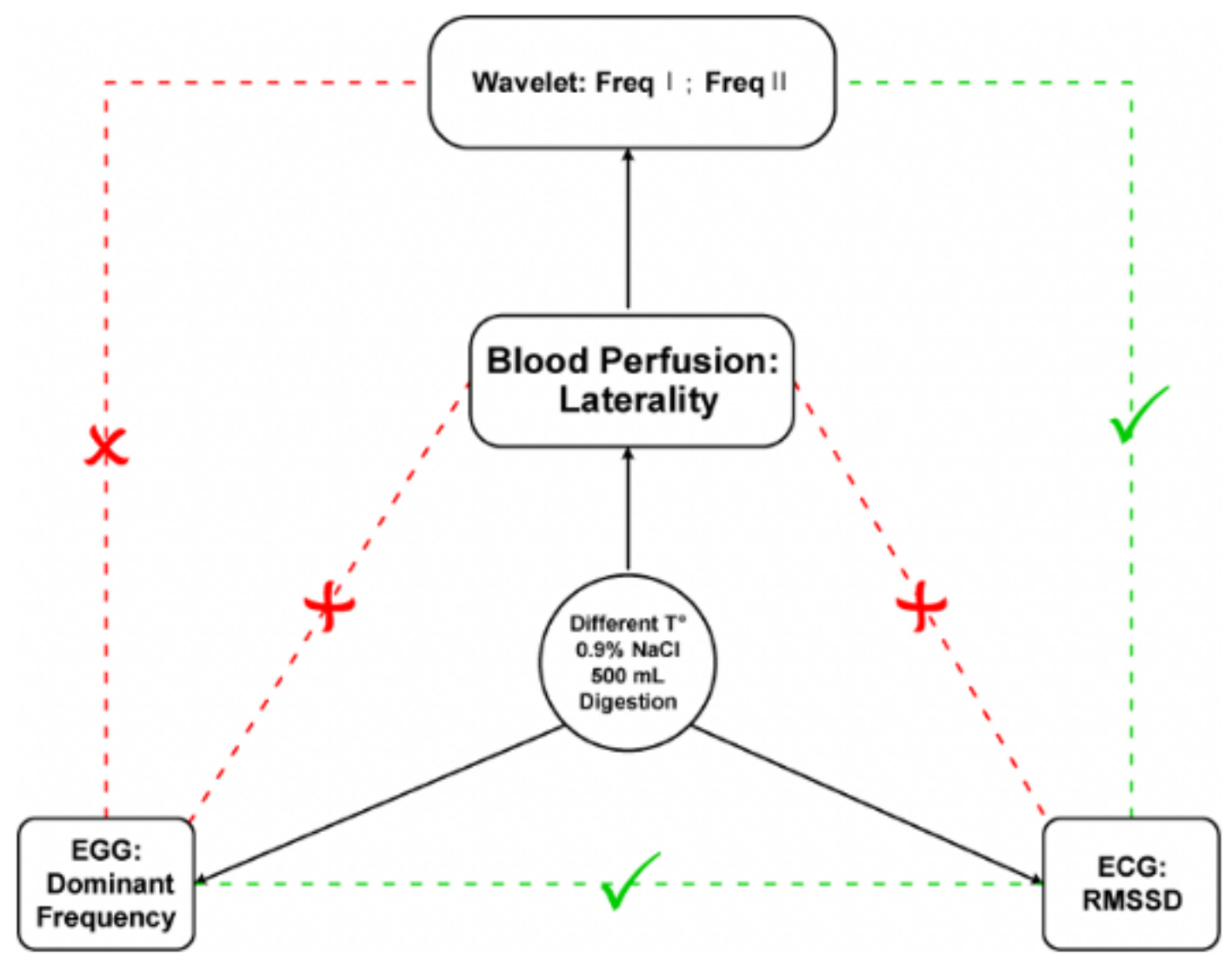

Figure 6

General illustration of the relationship. Under the different temperature conditions of saline ingestion, especially at $4{ }^{\circ} \mathrm{C}$ and $10^{\circ} \mathrm{C}$, the DF of EGG decreased, and the RMSSD of the RR interval increased. Especially under $4{ }^{\circ} \mathrm{C}$ saline ingestion, there was a weak positive correlation between DF and RMSSD, while there was no significant correlation between the laterality index of lower extremity blood flow and DF or RMSSD. Under the condition of $4{ }^{\circ} \mathrm{C}$ stimulation, there was a weak negative correlation between the laterality index of frequency interval I or II and RMSSD after wavelet transform. There was a weak positive correlation between the laterality index of interval II and RMSSD under the $30^{\circ} \mathrm{C}$ stimulation condition. It is concluded that the laterality of lower extremity blood flow is selective under different temperature conditions of saline ingestion.

\section{Supplementary Files}

This is a list of supplementary files associated with this preprint. Click to download.

- supplementaryfile.docx 